\title{
The Fact-Value Dichotomy: A New Light on an Old Problem
}

\author{
Georg F. Weber \\ University of Cincinnati, Cincinnati, OH, USA \\ Email: georg.weber@uc.edu
}

How to cite this paper: Weber, G. F. (2017). The Fact-Value Dichotomy: A New Light on an Old Problem. Sociology Mind, 7, 154-170. https://doi.org/10.4236/sm.2017.74011

Received: July 25, 2017

Accepted: August 21, 2017

Published: August 24, 2017

Copyright $\odot 2017$ by author and Scientific Research Publishing Inc. This work is licensed under the Creative Commons Attribution International License (CC BY 4.0).

http://creativecommons.org/licenses/by/4.0/

\begin{abstract}
Two highly visible, but conflicting concepts of morality have found widespread acceptance in philosophy. Socrates identified goodness with wisdom, holding lack of knowledge responsible for all moral mistakes. David Hume contrasted prescriptive with descriptive judgments, leading him to the conclusion that the former, unlike the latter, are not rationally supportable. It has often been missed that the acceptance of both, Socrates' teachings and Hume's law, generates a conflict, as elements of these two concepts contradict each other. It would appear prima facie obvious that mankind has learned from history how to coexist and make societies more just. Hence, there must be an empirical component contained in morals. Today, we have data that are reflective of certain elements of social justice. Measurables like crime rate, range between high and low income brackets, unemployment et cetera can serve as quantitative indicators for individual components that contribute to social justice. Such evidence corroborates at least a restriction on Hume's stance, if not an outright negation. Because there are rational and empirical elements underlying morality, thought models need to be calibrated against the real world for validation. The discussion, what constitutes progress and social justice, must consult history and research-not ideology-as sources of justification. Philosophy and the sciences must cross-fertilize each other.
\end{abstract}

\section{Keywords}

Social Justice, Progress, Fact-Value Dichotomy, Morality, Moral Code

\section{Introduction}

What is justice? Who or what provides the authority or the yardstick to make this assessment? Barely a question can be considered more fundamental for human coexistence in general, and for the coexistence in highly civilized technological societies in particular. Yet, the fundamentals of ethics-their foundation in 
authority, in knowledge or in sentiment-have been subject to extensive debate for 2000 years and more.

Moral reasoning is commonly described as embracing four components, moral sensitivity, moral judgment, moral motivation, and moral character. Implicit in this categorization of implementation is some level of agreement on what constitutes moral choices; that is some agreement on the goal post of a moral ideal, which needs to be laid down in a set of regulations, and over which a consensus can be formed. Measures of morality comprise written rules (a code of law) and general unwritten principles (such as fairness and honesty). Along these lines, Karl Marx juxtaposed the legal system, implemented by state power (force), to the prevailing moral system, sanctioned by an ideology (persuasion).

\subsection{Dichotomy between Descriptive and Prescriptive Statements}

Rooted in the teachings of the sophist Protagoras ${ }^{1}$, it has been widely accepted in philosophy that normative rules cannot be formally derived from facts. Hence, there is no precise definition for the connotations of ethical behavior, a term belonging to the realm of normative rules. Along the same lines of thinking, much of the $20^{\text {th }}$ century reflection on the subject embraced the philosophy of ethics by David Hume, which contrasted moral (prescriptive) with factual (descriptive) judgments, leading to the conclusion that the former, unlike the latter, are not rationally supportable (Hume, 1751). Hume found that there seems to be a significant difference between descriptive statements (about what is) and prescriptive or normative statements (about what ought to be), and that it is not obvious how one can coherently move from the descriptive statements to the prescriptive ones. Hume put forward the "is-ought" problem (Hume's Law), negating the possibility of logically deriving what ought to be from what is ${ }^{2}$.

Hume proposed sentimentalism as a foundation for ethics, primarily as a meta-ethical theory about the epistemology of morality (akin to the moral epistemology of intuitionism). According to such a theory, one's epistemological access to moral truths is not primarily via an evidentially mediated faculty, such

${ }^{1}$ Protagoras expressed the notion that judgments and knowledge are in some way relative to the person judging or knowing. As a consequence of his agnosticism and relativism, he may have considered that laws were things, which evolved gradually by agreement and thus could be changed by further debate. This position would imply that there was a difference between the laws of nature and the customs of humans. These notions have been very influential, and are still widely discussed in contemporary philosophy.

"'In every system of morality, which I have hitherto met with, I have always remarked, that the author proceeds for some time in the ordinary ways of reasoning, and establishes the being of a God, or makes observations concerning human affairs; when all of a sudden I am surprised to find, that instead of the usual copulations of propositions, is, and is not, I meet with no proposition that is not connected with an ought, or an ought not. This change is imperceptible; but is however, of the last consequence. For as this ought, or ought not, expresses some new relation or affirmation, "is necessary that it should be observed and explained; and at the same time that a reason should be given, for what seems altogether inconceivable, how this new relation can be a deduction from others, which are entirely different from it. But as authors do not commonly use this precaution, I shall presume to recommend it to the readers; and am persuaded, that this small attention would subvert all the vulgar systems of morality, and let us see, that the distinction of vice and virtue is not founded merely on the relations of objects, nor is perceived by reason" (Hume, 1738). 
as reason. Rather, truths are known via feelings of approval or disapproval. On Hume's premise, by inference, the rational debate over issues of morality and justice would be of very limited value as it could possibly push back, but never bridge the inherent gap between facts and norms.

Hume's arguments against founding morality on reason have had a profound impact on the ensuing thinking. They are often included in the category of moral anti-realist opinions. For there to exist moral facts about the world, recognizable by reason and intrinsically motivating, they would have to be very queer facts $^{3}$. G.E. Moore declared that any attempt to locate moral truths in the natural world was to commit a naturalistic fallacy. He argued that goodness could not be equated with any property of human experience, because it would always be appropriate to ask whether the property on offer was itself good ${ }^{4}$. Hume's law is also at the root of contemporary claims that statements about human values are without truth conditions, therefore not permitting moral judgments (rather than denoting moral truths, reference is made to moral preference or moral opinion).

Hume made an important intellectual contribution by recognizing that deductions of logic do not suffice to lay a seamless and coherent foundation for morality. Nevertheless, the anti-realist philosophies derived from his position have made it broadly apparent that a sentimentalist basis of ethics is untenable for supporting coexistence, because consensus cannot be forged devoid of rationalism. In recent decades, therefore, disagreement has been voiced increasingly with Hume's concepts ${ }^{5}$. Rather than relying on logic alone, philosophers and scientists have sought broader scientific underpinnings for morality.

The rapidly growing research insights of the $20^{\text {th }}$ century caused increasing unease with the anti-rational elements of Hume's law, initially without overthrowing the dichotomy between knowledge and values. Jacques Monod recognized that ethics has historically been based on animism, the belief in a supernatural power that organizes and animates the material universe. Science has caused a conflict in modern society by replacing animism as the source of knowledge, whereas the foundations of value judgments still remained tied to it (manifested in Judeo-Christian beliefs in Western countries and in historical materialism in communist countries). It was inevitable that scientific progress eventually undermined the mythical and philosophical ontogenies that had traditionally dictated norms and values. As a result, a value system was required that was consistent with the research enterprise and devoid of mythical beliefs. Monod demanded that the success of research for improving all aspects of society requires the foundations of ethics to be totally revised. Morals and science

\footnotetext{
${ }^{3}$ John Mackie.

${ }^{4}$ The concept is known as Moore's open question argument.

${ }^{5}$ Hilary Putnam consented to the usefulness of the fact/value distinction, but denied that anything metaphysical follows from it. Rather, he argued that epistemic values are also values. When we decide that scientific judgments must be coherent, plausible, reasonable, and simple, we draw normative judgments about how we ought to reason. Coherence and simplicity and the like have value characteristics themselves. What is considered to be reasonable may be objective in a conventional sort of way, but such decisions carry value judgments at their every turn. "[...] what is valid for inquiry in general is valid for value inquiry in particular" (Putnam, 2002).
} 
must not stand apart as unrelated. In communication and action, knowledge and values are always necessarily interconnected (every action serves certain values or reflects certain value judgments, while also being based on the knowledge of the actor). Further, the definition of true knowledge is based on the ethical demand for truth (the postulate for objectivity is a moral request that attributes a normative value to the quest for knowledge). Authenticity becomes the area where knowledge categories and ethics categories meet by connecting, but not mixing values and facts. Authentic speech enables research and is founded on principles of ethics (Monod, 1985).

\subsection{Knowledge as the Underpinning of Morality}

Contrasting with the philosophies of Protagoras and Hume, there are lines of thinking-rooted in ancient philosophy-that attribute a rational basis to morality. Socrates claimed that the rational part of the soul or mind must govern the spirited, emotional and appetitive parts in order to guide all desires and actions to eudaimonia, the principal constituent of which is virtue. He defined virtue as comprising prudence, justice, fortitude and temperance. Moral consistency and personal integrity should lead to repeated examination of one's views, in an effort to render them coherent and at the same time defensible on all sides through appeal to plausible arguments. Socrates claimed that self-knowledge is the sufficient condition to the good life. In identifying goodness with wisdom, he held lack of knowledge responsible for all moral mistakes ${ }^{6}$. Virtue consists in knowing and in thinking well (virtue is one with happiness), and the virtues are all sure and true knowledges. If knowledge can be learned, so can virtue. This led him to infer that moral excellence can be taught, a perception that has been widely embraced by spiritual and secular concepts of morality alike. Socratic ethics has an outcome-oriented character: human action aims toward the good in accordance with purpose in nature.

In a rationalist philosophy of more recent years, it has been proposed that human well-being ${ }^{7}$, the goal of morality, entirely depends on events in the world and on states of the human mind. Therefore, scientific truths must exist to describe it $^{8}$. The understanding of these truths forces clear distinctions between more or less ethical ways of living. Such scientific insights have the potential to ${ }^{\overline{6}}$ The Socratic Paradox states in essence that people act immorally, but they do not do so deliberately. No one chooses evil or chooses to act in ignorance. We seek the good, but fail to achieve it by ignorance or lack of knowledge as to how to obtain it.

${ }^{7}$ Progress and social justice are largely equivalent to human well-being (Sam Harris), the betterment of the community (Karl Popper), or the good life (Socrates).

"'Morality and values depend on the existence of conscious minds-and specifically on the fact that such minds can experience various forms of well-being and suffering in this universe. Conscious minds and their states are natural phenomena, of course, fully constrained by the laws of Nature (whatever these turn out to be in the end). Therefore, there must be right and wrong answers to questions of morality and values that potentially fall within the purview of science. On this view, some people and cultures will be right (to a greater or lesser degree), and some will be wrong, with respect to what they deem important in life", “[...] questions about values [...] are really questions about the well-being of conscious creatures. Values, therefore, translate into facts that can be understood", "The most important of these facts are bound to transcend culture" (Harris, 2010). 
improve the quality of life. Sam Harris recognized that, besides elucidating facts, science can support efforts at answering moral questions and may educate about how we ought to think. The more we understand ourselves at the level of the brain, the more we will see that there are right and wrong answers to questions of human values. The division between facts and values is intellectually unsustainable, especially from the perspective of neuroscience.

Two highly visible, but conflicting concepts of morality have found widespread acceptance in philosophy. Socrates identified goodness with wisdom, holding lack of knowledge responsible for all moral mistakes. This led him to infer that moral excellence can be taught, a view that has been widely embraced by spiritual and secular concepts of morality alike. On the other hand, David Hume contrasted prescriptive with descriptive judgments, leading him to the conclusion that the former, unlike the latter, are not rationally supportable as it is not obvious how one can coherently move from the descriptive statements to the prescriptive ones. Hume put forward sentimentalism as a foundation for ethics. His views have dominated the philosophical discussion of the past century. It has often been missed that the acceptance of both, Socrates' teachings and Hume's law, generates a conflict, as elements of these two concepts contradict each other. If morality is teachable and attainable through wisdom it must have an empirical or rational component. By contrast, if sentimentalism underlies morality then it is no more teachable than an art form. In this case, it would not be rationally or empirically justifiable.

\subsection{The Observational Basis for Knowledge}

In the empirical sciences, observation is the fundamental validator'. Observation-based tests of hypotheses are at the heart of generating knowledge. A statement that cannot be tested by experience qualifies as metaphysical and is excluded from the research discourse. New insight always originates in a hypothesis and is deduced there from according to logic (the rules of thought) and methodology (the rules of inquiry). As hypothesis-free observation does not exist, research progresses from hypotheses (which in philosophical terms are the prior) to deductions and observations that are coherent with them. For formulating coalescent theories, there are $^{10}$ rules that govern how hypotheses may be built into theories (mutually non-contradictory hypotheses on the same subject). The

${ }^{9}$ Testable propositions are also key elements of the empirical approach to morality. The proponent of pragmatic ethics, John Dewey, held that value judgments express propositions, which are subject to empirical testing and verification. But they are not merely descriptive; their essential function is to guide conduct. Value judgments can be both empirically warranted and action-guiding because they have an instrumental form. They say that if something were done, then certain consequences would follow, which would be liked or valued. Propositions of this form can be tested. The point of making such propositions is to decide upon a course of action that will solve a problem, where the proposition itself is part of the means by which the action is brought about.

${ }^{10}$ The ideal theory of the world, while always incomplete, will be inherently flawlessly consistent. This requirement is mandated by the recognition that a single antinomy is sufficient to derive ("prove") any conclusion whatsoever. We speculate that there is only one such possibility. Implied in this model is the notion that scientific progress is accomplished by addressing and eliminating inconsistencies (Weber, 2013). 
hypotheses of the set must be unconditionally consistent, as a single antinomy would suffice to prove anything - even two statements that contradict each other (Meschkowski, 1984) Furthermore, science must also permanently question and reexamine the original hypotheses and their roots. A hypothesis not supported by experience will be replaced by another hypothesis. Hypotheses confirmed by experience will be preserved. Whenever a conflict arises between hypothesis and observation or between hypotheses, it will be resolved empirically through experiment/scientific observation. The process allows theories to evolve far from the originating hypothesis (an evolution, which ideology is incapable of). In the background are premises that are assumed as having been confirmed. The empirical science of ethics can be built on the premise that morality is constituted of two founding goals, progress and social justice. Hypotheses regarding what constitutes these fundamentals can be formulated and tested. Moral decisions are made on the basis of measurables, which evaluate the stated hypotheses. As such, ethics is subject to hypothetical-deductive reasoning, inductive inference and empirical testing.

The circumstance that observation is never hypothesis-free reflects a constraint of the human mind. With the hypothesis acting as a starting point (the prior), it could be argued that scientific observation is only minorly different from ideology, which uses an idea as its starting point. Depending on how a hypothesis is phrased, the argument goes, the resulting observation is limited in scope and may be construed as biased at the outset. However, a key difference from ideology is that hypotheses can be weakened or strengthened by observation. Contrary to the hypotheses employed by a pragmatist and researcher, the ideas that form the foundation in the belief system of an ideologist do not adjust to conflicting observations. Rather, ideology tries to alter the observable to fit into the confines of its own preconceived thought model-an approach that is incompatible with scientific inquiry. Ideologies are formulated by their founders, and are often proclaimed to be unadjustable to conflicting evidence (a code that is proclaimed to be unchangeable is inconsistent with morality).

\subsection{The Empirical Element of Morality}

It seems prima facie obvious that mankind has learned from history how to coexist and make societies more just. Our complex communal structures, which entail laws and social security measures to support progress and social justice, have evolved to improve our lives over those of our predecessors. This development has not been imposed by some form of authority (as is implied in the philosophy of historical relativism), it has been truly developed from experience of past injustice and its consequences. Hence, there must be an empirical component contained in morals, which transcends culture and faith (broadly negating the contentions of relativist philosophies). This recognition raises the question whether ethics is fully derivable from experience, or observation just provides the boundaries for a sentimentalism that is not further rationally supportable. Today, we have data that are reflective of certain elements, which contribute to 
social justice. Measurables like crime rate, range between high and low income brackets, unemployment et cetera can serve as quantitative indicators for individual components that form our understandings of progress and justice. Such evidence corroborates at least a restriction on Hume's stance, if not an outright negation.

The contribution by David Hume lies in the recognition that the framework of logic is insufficient to provide a connection between facts and norms. His major oversight lies in having neglected that the tautologies of logic only provide a formalism for coherent argumentation, which is not equipped to make observations about the world. The validity of an argument is determined by its logical form, not by its content. Discussions regarding morality require the larger foundation of scientific inquiry - the means for understanding the world. Research always originates in a hypothesis and is deduced there from according to the set rules of logic and methodology. Logic is common to all sciences and assures consistency. The methodology, being unique to each branch of science, provides the empirical component (the observation). The starting hypothesis is strengthened or weakened by the preponderance of evidence obtained in the study. Knowledge is built through the formulation of coalescent theories as mutually consistent sets of hypotheses (Weber, 2013). In the background are premises that are taken as a given (e.g. the premise that the laws of nature, which were valid yesterday, will also apply today and tomorrow).

The empirical science of ethics can be built on the premise that morality is constituted of two founding goals, progress and social justice. These terms are broad and require definition, the components that contribute to them need to be dissected. Any definition of these two cornerstone elements or their constituents could be considered a hypothesis. Once hypotheses are formulated regarding the characteristics of progress and social justice, they are tested with the methodology tools available to the relevant branches of research. Data are collected by the social sciences to test the hypotheses through evidenc ${ }^{11}$. Such data can be used to strengthen or weaken the hypotheses and morality becomes a positive science ${ }^{12}$. As such, it is subject to hypothetical-deductive reasoning, inductive inference ${ }^{11}$ Ongoing discussions in the United States on the proper extent of government programs (health care social security, education, etc.) and their suitable sources of funding (taxes, debt) are, in principle, empirically testable through historical data on domestic programs and contemporary data on foreign programs. The programs that have been identified as most effective offer themselves for being adopted.

${ }^{12} \mathrm{~A}$-rather arbitrary-distinction has been made between positive science and normative (prescriptive) science. All material sciences (including physics, chemistry, biology, mathematics) are pure, abstract and positive sciences. Social sciences (like economics, politics, philosophy, history) attempt to analyze human behavior, which can be unpredictable. Therefore the degree of positivity is expected to be lower. Positive economics is objective and fact based (its statements can be tested and corroborated or weakened), while normative economics is subjective and value based. This distinction contains the seeds of Hume's fact/norm dichotomy. It attempts to classify linear models of the world (which have closed form solutions) as positive science, while separating non-linear phenomena (which cannot be solved formally) as normative. Research into non-linear systems dynamics, which has flourished since the 1960 s has made such a classification untenable. We believe that all science is positive science and reject the distinction as obsolete. 
and empirical testing ${ }^{13}$. Thus, our justification of norms, contrasting from Hume's, can be based on factual observations ${ }^{14}$. The notion, that an action is to be judged as moral if it supports societal progress (which entails, but goes beyond technological progress) and social justice, ties the concept of morality to measurables and thus opens the door to a rational discourse on the subject. Arguments in favor of or against specific norms are strengthened if they are founded on supporting data.

Why is there so much argument over ethics? Science always has room for discussion and disagreement. Extrapolations, differences in interpretation, and deliberations on definition are accepted elements of all empirical sciences. This also applies here ${ }^{15}$. The components that constitute social justice or progress may be subject to debate-a debate that can be supported and fortified by experience, but due to its complex nature will not arrive at definitions that are beyond further discussion ${ }^{16}$. Such elements do not infringe on the conceptualization of morality as defined by outcome and supported by experience, they contribute to refining the meaning of morality. Even if discrepancies in opinion remain among stakeholders, they will be increasingly constrained by accrued observation.

Hume's law disregards that history clearly shows norms being subject to empirical evaluation. It is hardly deniable that the experience of history has influ-

${ }^{13}$ The scientific method is based on logic and methodology. Logic comprises deduction (the derivation of conclusions from first principles) and methodology comprises induction (the inference of general rules from repeated observations). While deduction is more rigorous than induction (as elaborated by Karl Popper (Popper, 1982), research depends on both mechanisms.

${ }^{14}$ Basing values on knowledge is the tenor of many current philosophical approaches: "My goal is to convince you that human knowledge and human values can no longer be kept apart. The world of measurement and the world of meaning must eventually be reconciled. And science and religion-being antithetical ways of thinking about the same reality-will never come to terms. As with all matters of fact, differences of opinion on moral questions merely reveal the incompleteness of our knowledge; they do not oblige us to respect a diversity of views indefinitely" (Harris, 2010: p. 10).

${ }^{15}$ Moral skepticism has had a history of questioning the goals of moral theories, as well as the meaning of the words used to describe such goals. Hence, the meaning of "progress" and "social justice" might be questioned, and doubt might be cast on their legitimacy as time- and culture-overarching goals of morality. It is important to note that in other empirical sciences comparable fundamentalist objections exist (for example, the denial of evolution by Creationists), but seem to carry much less clout than is the case in discussions over morality and ethics. To exemplify the point, medical research has made progress in improving human well-being, regardless of how well-being is defined and why we should value it. Hence, the recourse to data is so important in the empirical science of ethics.

${ }^{16} \mathrm{Non}$-finality is a characteristic shared by all sciences. In no field of investigation will a premise ever satisfy the philosophical desire for precise definitions within refined thought systems. Contrary to the traditional philosophical debate, the understanding of morality as empirical does not attempt to offer a precise definition of the terms progress and social justice, but it develops a method how our understanding of these key elements of ethics can be improved through investigation and rationally communicated. This scientific model is consistent with the practice in all fields of inquiry. The cosmological premise that the universe is (or is not) finite cannot be answered definitively, but elements thereof, such as the question whether it expands or contracts can be-and have been tested. In cancer research, the premise that cells turn cancerous when biological control mechanisms break down will not be subject to irrefutable proof. Such proof, if it existed, would be of little practical value, but hypotheses can be formulated and tested as to what these control mechanisms are. In fact, this is how cancer research progresses. 
enced contemporary standards of justice and progress. Arguably, humanity has learned from the past, and today civilized societies accept that slavery and racism are immoral, women have shown their skills to not be inferior to men, and tyrannies have been found to infringe on key factors that define progress and social justice. Thus, morality can be treated as an empirical science. The longer diverse societies of mankind exist, the more experience accrues, regarding which formats do or do not support social justice and progress ${ }^{17}$. Evidence corroborates that certain communal structures are unsuitable for coexistence (a basic component of morality, as social justice does not occur without it). If coexistence is not supported then tension arises and leads to conflicts that, on a large scale, may manifest in wars.

The empirical element, which has allowed societies to learn from past mistakes, and the rational element, which has enabled putting into place structures that avoid, or at least counteract a relapse into unjust systems, are not accounted for in Hume's law. The foundation of morality on factual observations builds a bridge to Socrates insofar as the knowledge gained from cumulative experience shapes a growing basis of observables for moral decision making, and hence is explorable as well as teachable. Powerful influence on public policy decisions that affect progress and social justice is possible through ethics research ${ }^{18,19}$.

\footnotetext{
${ }^{17}$ Sometimes perceptions vacillate through the course of history, in the process generating knowledge and understanding, which inform future actions that promote social justice. Slavery was one considered appropriate, but is now punishable in all civilized societies. The Industrial Revolution bred capitalism and generated an exploitation of the working class that was reminiscent of slavery. This prompted Karl Marx to develop his anti-capitalist theories, which laid the foundation for the societal structure of communism. Consecutively, the big social experiment of communism-conducted in the Eastern Bloc countries after World War II-has been found empirically to be unsuccessful in instating social justice and progress. Within about half a century, it was replaced in the vast majority of countries that attempted its realization. However, some of its elements, such as the organization of labor, have been proven effective in avoiding a repeat of exploitation, and have been preserved. Thus, observation is a legitimate and powerful basis for moral judgment and implementation.

${ }^{18}$ Recent studies using the World Top Incomes Database have supported the conclusion that inequality does not follow a deterministic process. Powerful forces in the form of institutions or policies can be applied to affect outcome. Societies have to do the necessary analyses and decide which ones are likely most effective to adopt (Marshall, 2014).

${ }^{19}$ Research can support a successful active management of social evolution. To achieve the same reduction of poverty, the gross domestic product (GDP) of a highly unequal country like Brazil needed to grow at least twice as much as a more equal country (such as, for instance, Poland). The high level of inequality in South America required Brazil to adopt measures of pro-equity growth to reduce poverty by growing the gross domestic product. Policy measures included grants to boost education and achieved an increase in average years of schooling, including among the poor. The program allowed a reduction in inequality and an increase in social justice in the 1990s. This Latin American success at easing inequality has shown that government involvement is key for this process. Substantial measures in education and the social welfare system are required in the endeavor of building a supportive infrastructure (Hvistendahl, 2014). The investment pays off. The World Bank estimates that-for developed countries-a doubling of invested infrastructure capital raises the gross domestic product by 7 - 15 percent. By contrast, the involvement of the United States government was lacking in the two peak years of inequality over the past century (1928 and 2007), when the most affluent $1 \%$ of citizens garnered more than $23 \%$ of total income. Each of these periods was preceded by substantial increases in borrowing, which ended notoriously in the Great Crash of 1929 and the near-meltdown of 2008 (Reich, 2014).
} 


\subsection{A Rational Approach to the Evaluation of Morality}

Immanuel Kant asserted in his Critique of Pure Reason that claims, which cannot possibly be checked by experience are liable to produce a lack of knowledge. When leaving the field of experience, every argument has an equally valid counter-argument. Concepts of morality that are not based on experience become sterile dogmata, over which a rational discourse is futile. Irrationalism must tend toward dogmatism because the dismissal of argument leaves only two options, full acceptance or flat denial of a position. Rationalism is required in the debate over moral values because it critiques in a structured manner and allows for a change in position if swayed by the power of a stronger argument.

It is important to realize that an inability to answer a question at a particular time does not negate the possibility that the question itself does have an answer ${ }^{20}$. What limits the derivation of norms from facts is not a scientific impossibility. It is the need for existing complex data to be interpreted, and consecutively the inevitable need for extrapolation (induction) from past to future. Every critical analysis of the past or present provides a basis for future moral actions ${ }^{21}$. As collective wisdom (experience) grows, societies that incorporate it will reach higher moral standards. Beside the empirical foundation, an added benefit of this view of morality is the incorporation of an element of progress. Just like science and technology are shaped by experience, so is morality. It is possible to reach higher moral standards through empirical evidence and scientific analysis.

\section{Distinct Moral Foundations}

Two diametrically opposing models that are used as origins for societal decision making are pragmatism and ideology. For determining a plan of action on any issue of ethics, these distinct concepts provide foundations in support of conflicting strategies. They also provide conflicting foundations for moral codes.

\subsection{Pragmatism}

Pragmatism is a method that assesses the truth and meaning of theories or beliefs in terms of the success achieved by their practical application. In doing so, it is analytical and is guided by observation. Such a methodology supplies scientific backing (which is implicit in the common use of the term pragmatism). The approach requires the application of reflective intelligence to revise one's judgments in light of the consequences of acting on them. It is independent of social

\footnotetext{
${ }^{20}$ The distinction is made between there being answers in practice and there being answers in principle to specific questions.

${ }^{21} \mathrm{~A}$ process of learning from past mistakes has taken place in financial regulation. Before the great depression of the 1930s, central banks were entirely autonomous and had only one goal, which was the stabilization of the currency. They were willing to accept inhumane levels of unemployment to achieve their objective. Having learned from the experience, today's central banks in the Western industrialized world are appointed by their governments and act autonomously (to eliminate dictates by politics), but their objectives are given to them by parliament (Weldon, 2013). In the United States, accounting for past experience, the central bank's dual mandate today comprises full employment and price stability.
} 
class or epigones. Because pragmatism employs criteria that are situational, not a priori or universal, the argument has been made that pragmatic views effectively turn with the wind and, for lack of a solid basis, are at risk of morphing into opportunism. This is not a valid criticism if the pragmatic approach is based on the rational and empirical analysis of problems at hand.

Pragmatic ethics is a theory of normative philosophical ethics. Testable propositions are the key elements of the empirical approach to morality. John Dewey, a proponent of pragmatic ethics, held that value judgments express propositions, which are subject to empirical testing and verification. But they are not merely descriptive, their essential function is to guide conduct. Value judgments can be both empirically warranted and action-guiding because they have an instrumental form. They state that if something were done then certain consequences would follow, which would be valued or would generate a value. Propositions of this form can be tested. The point of making such propositions is to decide upon a course of action that will solve a problem, where the proposition itself is part of the means by which the action is brought about. Ethical pragmatists, such as John Dewey, believe that some societies have progressed morally in much the way they have attained progress in science. Scientists can pursue inquiry into the truth of a hypothesis and accept the hypothesis, in the sense that they act as though the hypothesis were true. Nonetheless, they think that future generations can advance science, and thus future generations can refine or replace (at least some of) their accepted hypotheses. Similarly, ethical pragmatists think that norms, principles, and moral criteria are likely to be improved as a result of inquiry ${ }^{22}$.

\subsection{Ideology}

Sharply contrasting, an ideology is a system of doctrines, especially one that forms a basis for economic or political theory and policy. Ideologies entail normative visions that are considered the correct way by their adherents. Their purpose is not epistemic, rather they exist to confirm a certain viewpoint, to serve the interests of certain people, or to perform certain functional roles in society. Such roles can involve a process of justification that requires the obfuscation of reality. This lack of a grounding in the real world raises the prospect for all kinds of ideologies to be pseudo-validated, because fact checking is not part of their justification. In the absence of testable facts, a rational discussion is deprived of its basis. Some ideologies may be enforced by the dominant class of society (the elite) and serve the status quo, others may call for its reform or overthrow and reflect an uprising by a lower class of society ${ }^{23}$. Their influence is ${ }^{22}$ https://en.wikipedia.org/wiki/Pragmatic_ethics

${ }^{23}$ Daniel Bell dubbed ideology an action-oriented system of beliefs, which indicates its role is not to render reality transparent, but to motivate people to do or not do certain things. Karl Mannheim elaborated on the complex relationship between reality and ideology by pointing to the human desire for ideology. One of his key propositions was that the world is not given to us simply by our senses. We interpret it, through lenses based on culture, experience, and ideologies. Human notions of action and identity are affected by these biases. This circumstance plays directly on the relation between the self and society. 
dependent on the importance they have in the minds of their admirers and the reach given to them by their epigones (Monod, 1985). Ideology bears the risk of imposing dictatorships by forcing on the constituency thought models from the realm of totalitarianism.

Fundamentalism is a form of ideology that reflects the uncompromising adherence to a base creed. Bred from an unrealistic need for certitude and a fear of change, fundamentalism is motivated by a rejection of modernity (and its associated stress of dislocation) often combined with socio-economic grievances, which prompt ideological glorification. It may manifest in legislature and politics through the ascription of unchangeable validity to a constitution or to a dictate by a perceived leader. It may manifest in religion through strict literalism and the declaration of infallible truth being associated with the words of some prophet, regardless of how long ago those words were produced. Fundamentalism is inherently totalitarian, insofar as it seeks to forcibly remake all aspects of society (imposition of particular forms of worship or conduct) and government (frequently seeking violent overthrow) on ideological principles. Being anti-historical in its rejection of change, fundamentalism is in conflict with the reality of ever evolving societies in ever evolving environments. The sciences, including physics and chemistry that in past generations used to study reversible processes, have in fact come to the recognition that considering change over time is essential to our understanding of the world (Boltzmann, 1866; Prigogine, 1980).

Ideology is a weaker foundation than pragmatism-specifically for moral action-because it is not beholden to yield to conflicting observation (ideology strives to shape reality so as to fit into its own thought system), it is not amenable to open and rational discussion (ideology is dictated by its proponents), and it does not adjust to communal needs (the idea is perceived as more powerful than the individual). In its fundamentalist manifestation, ideology resists the change of time. Because of these characteristics, it conflicts with the empirical approach. Concepts of morality that are not based on experience and analysis become sterile dogmata (here understood as strong beliefs, which the ones adhering to are not willing to rationally discuss). The demarcation of scientific inquiry from ideology/dogma (including its fundamentalist manifestations) is critical in the justification of all moral codes.

\subsection{Moral Codes}

Codes may comprise rules explicated as laws ${ }^{24}$, philosophical systems that for-

${ }^{24}$ Throughout history, a mark of civilized societies has been their ability to refine laws such that they reflect the needs of the people. Laws change to keep up with the ever-evolving views and values of the society. An important role for lawmakers lies in identifying shifts in the expectations and values of the society so as to create and pass appropriate laws. This flexibility ensures that changes are in sync with their times (Malakoff, 2017). Various developments can necessitate new laws. As a case in point, over the span of a generation, improving computer capabilities have generated the internet and social media, which require specific laws (e.g. against hacking) that would have been aimless just a few years earlier. In order for the law to work, it must accommodate such changes. In general, laws rarely shape the society to which they apply, conversely however, social movements have lawmaking potential (Guinier \& Torres, 2014). 
mulate a destiny for society if it follows an outlined path ${ }^{25}$, or religious belief systems that sanction the instructions of sacred scriptures ${ }^{26}$. These three formats differ in their normative justifications (societal need and consensus for law, the prediction of an inevitable destiny for oracular philosophies, the belief in a law-providing god as the source for scriptures) and in their preparedness to evolve their norms. Among them, only law has room for pragmatic adjustments that further progress and social justice. At its core this is feasible because, in contrast to oracular philosophies and religions, law does not predict a destiny for mankind. It can be formulated to locate the conditions of warrant for our value judgments in human conduct itself, not in any a priori fixed reference point outside of conduct (such as in god's commands, nature, or platonic forms), considered as giving humans a predefined end point. Outcome prediction and reference points outside of human conduct are fundamental flaws in moral justification.

It is important to take into consideration some basic laws of nature regarding complex systems (Kauffman, 1993), such as are social structures. Because they do not progress on linear paths they do not permit simple mathematical solutions ("closed-form solutions"). The non-linearity of events in society does not allow for the precise predetermination of an outcome, even in the relatively near future. This limitation holds whether the predicting ideology is secular (oracular philosophy) or transcendental (religion). Since the enlightenment, the standards for scientific exploration have been increasingly developed, and the research discourse has produced vast insights that do not support predictions of a desired future. Although the open-endedness of the scientific endeavor (Eigen \& Winkler, 1985; Prigogine \& Stengers, 1984) may seem dissatisfactory to the adherents of philosophical system builders, it is the only rationally justifiable foundation

\footnotetext{
${ }^{25}$ Philosophies with oracular content prominently include the beliefs of Plato, Hegel, and Marx. For Plato, history equaled decline. Therefore, he desired to turn back time and reestablish a caste system, in which rulers govern, warriors fight, and slaves serve. The philosopher king is likely the role Plato envisioned for himself. For Hegel and Marx, history proceeds according to an immanent and necessary plan. Hegel served as an apologist for the Prussian kingdom. The system developed by Marx centers on a liberation of the working class. For individuals holding leadership positions, historical prophecy is flattering as it puts them into the inner circle of the initiated, the ones who possess the power of prediction. Not to possess it could lead to a loss of status. This type of caste system, albeit inferior to modern social structures, is almost inseparably implied in the acceptance of oracular philosophies. The concept is inherently unjust as it places its own proponents into the ruling class. Thus, such philosophies (referred to as historicism) constitute potentially dangerous ideologies that could propel their protagonists to become dictators (Popper, 1966).

${ }^{26}$ Spiritual concepts likely arise from mental categories that predate religion. They may be a manifestation of the human desire to understand the world, and to fill in the unknown with transcendental myths (Monod, 1985). Another root may be the difficulty to accept the limitation of the individual existence. The inevitability of facing death ever more closely as life progresses can be overcome by a firm conviction in the existence of an afterlife. Religious devotees generally believe that they possess knowledge of sacred truths, and every faith provides a construct for interpreting experience so as to lend further credence to its own doctrine. Adherents to particular religions relax their standards of rationality because certain doctrines are compatible with their processes of inference in such a way as to seem credible (Boyer, 2001). It is more important for a particular idea of god to work than for it to be logically or scientifically sound (Armstrong, 1993).
} 
for the evaluation of values, such as morality ${ }^{27}$.

The future is not predictable. Oracular philosophies that forecast the arrival of a structured society, ruled by their adherents, constitute illegitimate ideologies. Transcendental philosophies similarly anticipate an end state for humanity, one that is shaped by spiritual supernatural forces. In both cases, the prognostication of a better state as the outcome of a predetermined historical path is intended to validate the ideology. The idea that has fertilized the thought system is given higher importance than any possibility to test it against reality. While pragmatism also starts with an idea-the hypothesis, it collects data to test whether or not this hypothesis is corroborated by experience. If it is not confirmed by observation, the hypothesis will be dismissed. If it is strengthened, it will find entry into theories. No rational thought system is constructed outside of the observables. The future is accepted as undetermined.

The empirical basis would be negated if moral justification were based on the manifesto of a secular or religious ideology, because those ideologies intend not to be adjustable to their environment-much rather they strive to shape the environment to fit their belief system. This approach leads to a dictate imposed by the ideology.

\section{Conclusion}

David Hume contributed to our understanding by recognizing that logic is an insufficient basis for providing a connection between facts and norms. However, he missed that the tautologies of logic only provide a formalism for coherent argumentation, which is not equipped to make observations about the world. Discussions regarding ethics require the larger foundation of scientific inquiry, which constitutes the means for understanding the world. Mankind has learned from history how to live together and make societies more just. From experience, we have developed communal structures to support progress and social justice. Hence, morality has an empirical component that transcends culture and faith and is accessible to rational analysis.

Our response to overcoming the fact-value dichotomy is the definition of values as hypotheses and the analysis of their applicability with the tools of empirical research. Humankind's desire for coexistence has been accompanied by lessons from past instances of injustice and by the accessibility of quantitative indicators for actual social disparities. These factors enable a scientific approach to analyzing progress and social justice. Elements that constitute progress and social justice are quantifiable, and are thus accessible to research. Experience of the successes or failures by past social institutions also must guide contemporary moral decisions. Progress, in an ethical sense, becomes manifest through avoiding structures or actions that have caused injustice in previous attempts toward

\footnotetext{
${ }^{27}$ Karl Popper points out that the historicist attitude "must lead to a rejection of the applicability of science or reason to the problem of social life-and ultimately, to a doctrine of power, of domination and submission." This inescapable connotation of historicism leaves a scientific approach to morality as the only viable path to social justice.
} 
implementation or that are currently insufficient. A common fallacy of our culture has been the predisposition to discuss critical issues of communal management from the starting point of a preexisting, often prescriptive political ideology. The tendency to put conclusions ahead of data collection and analysis weakens the power of rational evaluation. Moral justification must be based on empirical reflection, not on the manifesto of an ideology (of political, transcendental or any other persuasion). Only scientific observation allows the adjustment of norms to the needs of the society. The proper methodology for this discourse is the scientific inquiry. Driven by hypotheses and the evaluation of measurables for progress and social justice, ethics can be understood as a positive science. As such, it is subject to the non-finality of all social sciences and requires continuous investigation.

The data-oriented approach to ethics may be dissatisfactory to traditional philosophers. Our concepts rely much more on the sciences than paying tribute to the large volume of available theoretical, philosophical publications. Philosophers and others have contended for centuries about what constitutes justice and progress, and they have often felt a requirement for stringent definitions of such phrases as progress and social justice. The proposition to treat these key entities as premises within a science of morality, which formulates and tests hypotheses as to what measurables constitute legitimate elements of progress and social justice, is counter to the classical philosophical approach and therefore not acceptable to some traditionalists. Yet, while the linguistic stringency that goes with mainstream philosophical works has its own value, the practice of ethics is not resolved with semantics. The academic discourse on the foundations of ethics has produced some remarkable works, but such discussions can extend ad infinitum if they do not engage sufficiently with the reality of existing social structures. Definitions are not the focus of the thought system expounded here, it is much rather centered on the method that is most suited to enable the improvement of our coexistence. The requirement to include data in the discussions over ethics is resultant from the very essence of the recognition that morality does have an empirical foundation. The concepts spelled out here represent a scientific approach, not final answers.

Traditionally, deliberations on ethics were largely conducted within faculties of philosophy. Almost entirely, they focused on a discourse over thought models. Normative ethics has been categorized into deontological ethics, teleological ethics and virtue ethics. Various schools have further subdivided each category, thus providing ample opportunity for uniquely academic discussions. Yet, the requirement to include data in the discourse is resultant from the very essence of the recognition that morality does have an empirical foundation. The investigation, what constitutes progress and social justice, must consult history and the sciences as sources for justification. After all, the acclaim of philosophy derives in part from its holistic consideration of the intellectual world, which is tied to the mandate to consider all available resources of knowledge. To take it one step further, all academic discourse strives to positively impact society. This is diffi- 
cult to accomplish if the implementation of discussions is confined to the ivory tower. For validation, thought models need to be calibrated against the real world; philosophy and the sciences must cross-fertilize each other.

\section{Acknowledgements}

This paper is an excerpt of the book: Weber GF. Progress and social justice-the empirical basis of morality. Cincinnati (MetaMol Publishing) 2017. ISBN-13: 978-1548294861, ISBN-10: 1548294861.

\section{References}

Armstrong, K. (1993). A History of God: The 4,000-Year Quest of Judaism, Christianity and Islam. New York: Ballantine Books.

Boyer, P. (2001). Religion Explained: The Evolutionary Origins of Religious Thought. New York: Basic Books.

Boltzmann, L. (1866). Über die MechanischeBedeutung des ZweitenHauptsatzes der Wärmetheorie. Wiener Berichte, 53, 195-220.

Eigen, M., \& Winkler, R. (1985). Das Spiel: Naturgesetzesteuern den Zufall. München/Zürich: Pieper.

Guinier, L, \& Torres, G. (2014). Changing the Wind: Notes toward a Demosprudence of Law and Social Movements. The Yale Law Journal, 123, 2574-3152.

Harris, S. (2010). The Moral Landscape: How Science Can Determine Human Values. New York: Free Press.

Hume, D. (1738). A Treatise of Human Nature. London: John Noon.

Hume, D. (1751). An Enquiry Concerning the Principles of Morals. London: Andrew Millar. https://doi.org/10.1093/oseo/instance.00037977

Hvistendahl, M. (2014). While Emerging Economies Boom Equality Goes Bust. Science, 344, 832-835. https://doi.org/10.1126/science.344.6186.832

Kauffman, S. A. (1993). The Origins of Order: Self-Organization and Selection in Evolution. New York/Oxford: Oxford University Press.

Malakoff, D. (2017). A Matter of Fact. Science, 355, 562-563.

https://doi.org/10.1126/science.355.6325.562

Marshall, E. (2014). Tax Man's Gloomy Message: The Rich Will Get Richer. Science, 344, 826-827. https://doi.org/10.1126/science.344.6186.826

Meschkowski, H. (1984). Was wirwirklichwissen. Die exaktenWissenschaftern und ihrBeitragzurErkenntnis. München: Pieper.

Monod, J. (1985). Zufall und Notwendigkeit. PhilosophischeFragen der modernenBiologie. München: DeutscherTaschenbuchVerlag.

Popper, K. R. (1982). Die Logik der Forschung (7th ed.). Tübingen: J.C.B. Mohr.

Popper, K. R. (1966). The Open Society and Its Enemies (5th ed.). Princeton: Princeton University Press.

Prigogine, I. (1980). From Being to Becoming. San Francisco: W.H. Freeman and Company.

Prigogine, I., \& Stengers, I. (1984). Order Out of Chaos. Man's New Dialogue with Nature. Toronto/New York/London/Sydney: Bantam Books.

Putnam, H. (2002). The Collapse of the Fact/Value Dichotomy and Other Essays. Cam- 
bridge: Harvard University Press.

Reich, R. B. (2014). How to Shrink Inequality. http://robertreich.org/post/85532751265

Weber, G. F. (2013). Dynamic Knowledge-A Century of Evolution. Sociology Mind, 3, 268-277. https://doi.org/10.4236/sm.2013.34036

Weldon, A. (2013). Words of Finance. Money Talks. London: Bene Factum Publishing. 